\title{
Adaptability of the Recloser-Fuse Protection Scheme in the Presence of Distributed Generation
}

\author{
Patrícia Santos e Abreu and António Gomes Martins \\ INESC Coimbra, Department of Electrical and Computer Engineering, Rua Sílvio Lima, Polo II, Coimbra 3030-290, Portugal
}

\begin{abstract}
This paper addresses the behaviour of an IEEE (Institute of Electrical and Electronics Engineers) test network when distributed injections are added to the distribution network. The penetration of different dispersed generation technologies, modifies the distribution system characteristics, with impact on a number of parameters, depending on their size and location on the network. For this purpose, this paper comprises three case studies: in the first case an exhaustive analysis is carried out of the occurrence of faults throughout the network, along with the introduction of distributed generators; in the second case the network behavior is assessed against the use of three of the most commonly used types of generators based on rotating machines; in the third case study an evaluation is made of the network performance when the three types of DG (distributed generation) units are distributed in multiple buses. In all cases the protection system is analyzed with the aim of ensuring coordination among the protection devices. All simulations are performed using the Power Factory software package from DigSILENT. From the simulation results, conclusions are drawn that provide insights into the behaviour of protection systems, highlighting the limitations of the original protections and coordination with different distributed generators technologies.
\end{abstract}

Key words: DG, protection coordination, DG technologies, power system protection.

\section{Introduction}

In recent years, the introduction of distributed production in the distribution network has been increasing in order to take advantage of the use of renewable energy sources. However, the usage of DG (distributed generation) is not only beneficial to electricity users, but also to utilities. Its advantages can be summarized as: increased voltage stability, loss reduction and higher overall efficiency, environmental benefits and low pollution [1].

The generators used to convert primary renewable energy to electricity may be asynchronous or synchronous generators, which can be used in thermal, hydro and wind generation plants. They can operate as a generator or a motor, since the electromechanical conversion of energy is always reversible [2, 3].

In spite of its benefits, DG integration, however,

Corresponding author: Patrícia Santos e Abreu, Ph.D. student, research fields: distribution network, power system protection and distributed generation. may have a significant influence on the coordination of network protection systems. Energy flow becomes bidirectional, the selectivity and speed of operation of the protection systems may be altered and thus make temporary faults to cause permanent disconnections of parts of the network, or to cause disconnection of larger portions of the network than needed when faults occur, affecting network quality of service.

Traditional protection systems are designed according to the network radial topology. With the introduction of DG, there are zones of the systems that will no longer follow this topology, which may lead to loss of coordination between protection devices. The effect of DG on coordination will depend on its capacity, type and placement. In the literature, several studies are focused on choosing the optimal size and location of DG units [4-8].

In the most unfavorable case to a DSO (distribution system operator), regulation will not prevent investors from defining DG placement sites, provided there are suitable technical conditions. The DSO may, then, not 
be able to influence DG locations from the perspective of the maximum benefit to the network. On the other hand, in many regions of the world, distribution companies are not fully engaged in network modernization investment through wide implementation of digital solutions, since financial resources are frequently scarce. Hence, there is a need to cope with new DG projects carried out by private investors, making the currently available protection systems technology cope with the new operating conditions caused by DG additions. Even when a DSO carries out planned network modernization, many sectors of the distribution system will, for extended periods of time, before modernization, keep operating with less up-to-date technology, simultaneously having to cope with new DG interconnections. The authors have dealt in a different publication [9] with the specific issue of the need to adapt the protection systems of distribution networks as seamlessly as possible to new DG interconnections, avoiding costly replacements or heavy investments.

The present paper proposes an operative approach to the assessment of the capacity of a distribution network feeder to accept DG additions without disrupting the existing protection system. It also analyzes the influence of different generating technologies, focusing on the three options most widely used in wind and hydro power: synchronous, asynchronous and doubly fed asynchronous machines. Three case studies are presented to reach the proposed goals: in the first case an exhaustive analysis of fault occurrences is carried out to assess the network performance when a fault occurs and DG is introduced into the test network; in the second case the behavior of three most commonly used types of rotating generators is analyzed and in the third case an evaluation is made of the network performance when the three types of DGs units are distributed through multiple buses.

The IEEE (Institute of Electrical and Electronics Engineers) 34 Node Radial Test Network was used as a test network where faults were simulated and DGs of various sizes were placed on all buses to allow the identification of the most critical DG locations and in order to evaluate the limitations of the original protections to respond to security, coordination and selectivity criteria, simulating short-circuits in all buses. Critical DG locations are those where the existing protection system does not respond adequately. Once the critical locations are identified, the performance of the generators is discussed, taking into account the technologies at stake: asynchronous generator, DFIM (double fed induction generator) and synchronous generator. Finally, the operation of the protections when integrating DGs into multiple buses was evaluated. The aim is to try to identify which technology presents fewer problems to the distribution network protections, when these are based on the recloser-fuse combination. All simulations are performed using the Power Factory software package from DigSILENT.

This paper is structured as follows: Section 2 presents the DG technologies considered. Section 3 describes how the coordination of protections is established. Section 4 presents the case study, protection scheme and DG model to apply. Section 5 shows simulations, sets out the results obtained for each case study together with discussion of the results. The conclusions are reported in Section 6.

\section{DG Technologies}

\subsection{Technologies}

DG technologies, to convert the energy obtained from renewable primary energy into electrical energy, can be based on asynchronous or induction machines, operating either based on SCIMs (squirrel cage induction machines), DFIM, or PMSMs (permanent magnet synchronous machines). According to Freitas et al. [3], most of the large generators used in hydroelectric, thermal and some wind turbines are synchronous machines. On the other hand, the same authors mention that a large part of the induction 
machines, in operation, are used in wind turbines. In the past they were also used in medium-sized hydroelectric, and thermal power stations.

The technology to be used in renewable energies depends on the frequency generated, due to the difference in rotational speeds, which can be of two categories: constant frequency of constant speed, the SCIM, or constant frequency of variable speed, with DFIM and PMSM [10].

The interconnection of DG is carried out with one of these machines and can be directly coupled to the network or can be interfaced through electronic converters. When connected to the power system, these DG technologies have different impacts on the operation, control and stability of the power system, affecting the size and location of DG units [4].

Some authors have compared types of technologies: Rizzo et al. [11] establish a comparison between different machines operating in stand-alone mode and connected to the distribution network; Freitas et al. [3] analyze the behavior of each technology through the network performance, in terms of steady-state voltage profile, power losses, voltage stability and short-circuit currents. Other authors [12-15] made comparisons when they operated as wind turbines of different technologies.

Comparing the two asynchronous machines addressed in this work some advantages of each technology are: SCIM does not use power electronics, making it more economical, using a gearbox to operate, unlike the others; DFIM is an attractive system from an economic point of view, showing an increase in efficiency, an improvement in the quality of energy and a control of active and reactive power [14-16].

It is possible to highlight some characteristics from the comparison between generators when converting renewable energy: in wind energy, asynchronous generators are always used with a gearbox whereas synchronous generators do not need this component; there can be variable speed in generators of both types; the wound rotor asynchronous generator, needs power
Table 1 Characteristics between asynchronous and synchronous generators [2].

\begin{tabular}{ll}
\hline Asynchronous machine & Synchronous machine \\
\hline Moderately efficient & Efficient \\
Less expensive & Expensive \\
Little maintenance & Requires maintenance \\
Sink of reactive power & $\begin{array}{l}\text { Reactive power flow can be } \\
\text { controlled through field current }\end{array}$ \\
$\begin{array}{l}\text { Suitable for week networks } \\
\text { only in conjunction with } \\
\text { power electronics }\end{array}$ & $\begin{array}{l}\text { Suitable for connection to weak } \\
\text { networks, used in autonomous } \\
\text { systems }\end{array}$ \\
\hline
\end{tabular}

electronics, while, on the other hand, the synchronous generator needs an electronic interface to provide a DC (direct current) link; in hydro, asynchronous generators require a gearbox. By using a synchronous generator it is possible to carry out reactive power control when necessary [2]. Some features of these technologies are presented in Table 1.

According to some investigations the DFIM dominates the large scale wind turbines market, while the use of PMSM is continuously increasing in small scale wind power, and the SCIMs are less and less used $[14,17]$.

\subsection{Impact of DG on Distribution Networks}

The introduction of DG can negatively affect distribution systems, through the redistribution of power flows, changes in short-circuit currents, overvoltage and faults in the protection systems. In the presence of DG a miscoordination of protections may happen, depending on the size, type and location of DG. This circumstance highlights the need of the DSO to have a strategy for treating existing protections in order to adapt them to the existence of new DGs, also taking into consideration the behavior of different generation technologies.

Approximate models of synchronous generators, used in small hydro DG, which are represented by a single driving voltage in series with equivalent impedance, are utilized for short circuit studies. The value of the equivalent impedance considered in the analysis depends mainly on the sought time frame of the analysis, i.e., on the values defined for the $X_{d}^{\prime \prime}, X_{d}^{\prime}$ 
and $X_{d}$ parameters, in subtransient, transient and synchronous periods, respectively. For asynchronous generators, used in wind turbines, the short-circuit current depends only on the subtransient values [18].

Short-circuit current levels in the presence of distributed power injections depend on the type of generators used in the DG construction. In Ref. [19], typical value ranges are presented of the ratio between the output current and the short-circuit current:

- Asynchronous machines: 100\%-400\%, the duration depending on controller settings and current.

- Synchronous machines: Starting at 500\%-1,000\% for the first few cycles and decaying to $200 \%-400 \%$.

- Induction machines: $500 \%-1,000 \%$ for the first few cycles and decaying to a negligible amount within 10 cycles.

Regardless of the cycle duration, high short-circuit current values can cause problems in the coordination of the protection system and affect the continuity of supply.

\section{Recloser-Fuse Coordination}

Protective devices, reclosers and fuses are installed in the main and lateral feeders, respectively, of the distribution network. For coordination between reclosers and fuses, the DSO can choose from two philosophies: fuse-saving scheme or fuse-blowing scheme [20].

In the literature, some authors report that the most widely used scheme aims at fuse preservation [21, 22], which will be focused in this chapter, illustrated in Figs. 1 and 2 . The coordination range of fuse and recloser is defined for all fault currents between $I f_{\min }$ and $I f_{\max }$. Within this range the recloser operates before the fuse, which corresponds to the required coordination.

The fuses have two main relevant characteristics in coordination analysis: MM (minimum melting) and TC (total clearing). The MM feature corresponds to the time required to begin melting the fuse for a certain value of the current passing through it. The TC feature corresponds to the fuse total melting time for a given

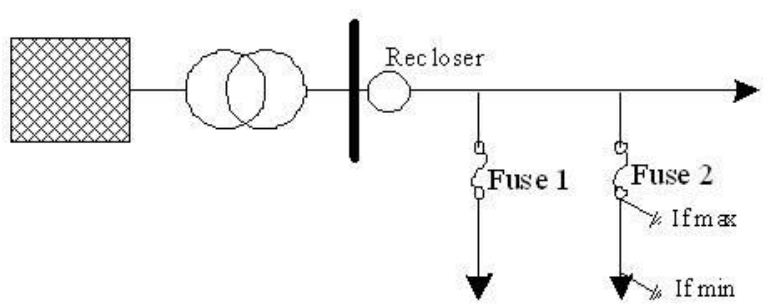

Fig. 1 Recloser-fuses radial distribution feeder (adapted from Ref. [23]).

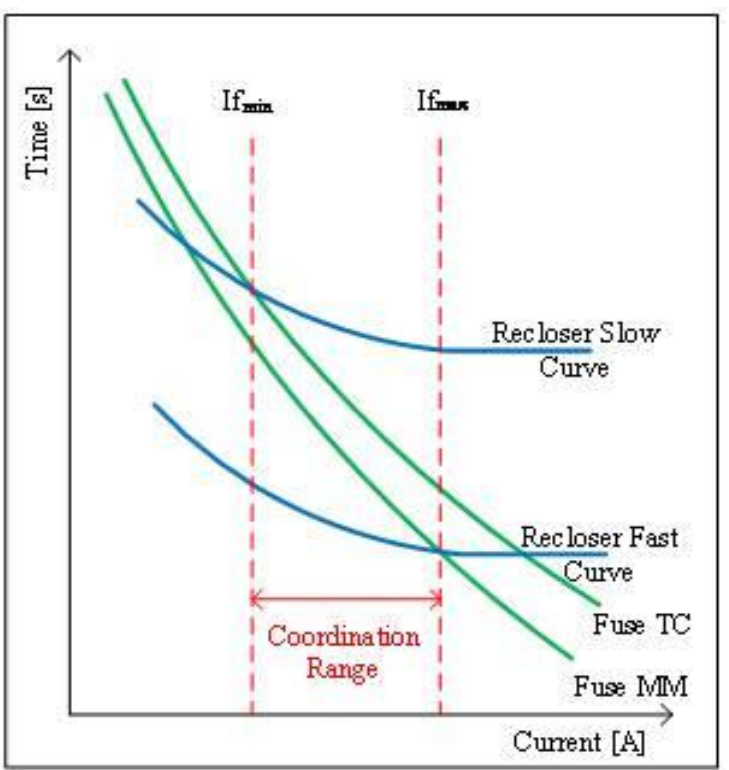

Fig. 2 Coordination between recloser and fuse.

value of the current flowing through it. The recloser operates according to two curves: fast and slow.

In this case, the recloser operates always before the fuse, i.e. the fast recloser curve is below the MM fuse curve. If the fault is permanent, after the recloser closes the circuit, the fuse must operate. Given that the fuse TC curve is below the recloser slow operating curve, in the case of a permanent fault the fuse should blow before the recloser operates (at its slow curve). If the fuse does not blow, the recloser shall operate according to its slow operating condition, acting in that case as a backup protection device isolating the fault.

\section{Study Case Description}

\subsection{Test Network}

The network test IEEE 34 Node Test Feeder is part of several networks described by a working group 
designated Distribution Test Feeder Working Group of the subcommittee IEEE Power \& Energy Society (PES) Distribution System Analysis Subcommittee, which can be used as base tests, in the present work carried out with the network simulation software, DigSILENT Power Factory 2018.

This particular network exists in the state of Arizona, United States, and has an unbalanced nature, a typical characteristic of distribution networks. With a base power of 2.5 MVA, it has two transformers, a 69/24.9 $\mathrm{kV}$ installed at the substation and the other 24.9/4.16 $\mathrm{kV}$ installed at a lateral, two voltage regulators strategically located on the network, two capacitor banks, six concentrated loads and nineteen distributed loads, of constant power, impedance and constant current types [24].

For the simulation of the test network some adjustments were made, according to Mwakabuta and Sekar [25], shown in Fig. 3. The power flow simulation results obtained were very close to the original. The test network presents a main feeder and four lateral feeders.

\subsection{Protection Scheme}

To select the characteristics of the various protection systems, three-phase short-circuits were simulated in Power Factory, using the "complete method" which is based on the superposition theorem to determine the short-circuit currents.

The locations of protective devices were set at the main feeder bus 800, and at the laterals, as shown in Fig. 3 . The locations are referenced by the network nodes' numerical codes.

The reclosers are usually designed with inverse time overcurrent curves, in this case that a Cooper Power Systems, model Form 4C having been chosen, placed on the main feeder, location P1 [9].

The characteristic curves of the fuses are those of the S\&C Electric Company, Positrol fuses, whose operating time and the fault current observed by the fuse are parameters that need to be configured. The fuses were adapted to each lateral characteristic (P2 to P6).

DGs protections were implemented with overcurrent relays of the General Electric IAC51804A model, available in the software library.

\subsection{DGs Models}

In order to connect distribution network to DG, a coupling transformer had to be configured to obtain a voltage of $400 \mathrm{~V}$, the DG rated voltage.

In the first case, in order to know the network protection system behavior when a fault occurs and a DG is connected, an exhaustive analysis was performed on the test network. Three types of DGs, all

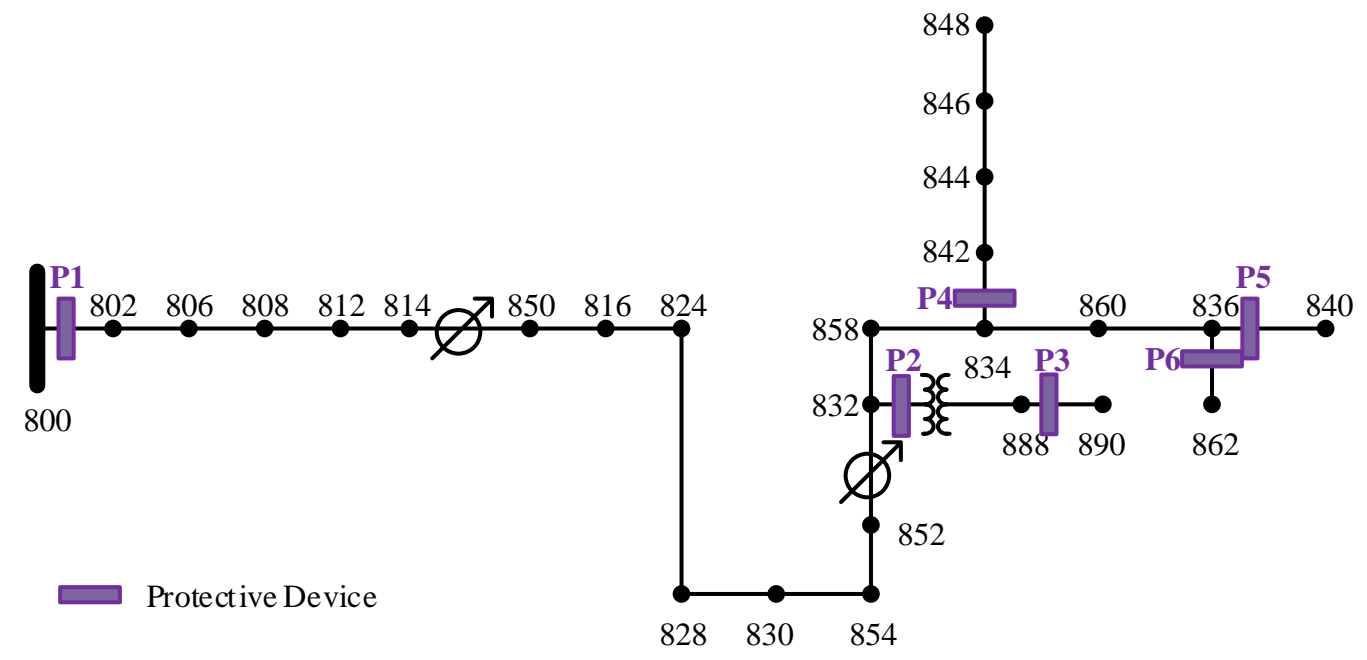

Fig. 3 IEEE 34 Node Test Feeder with protection devices. 


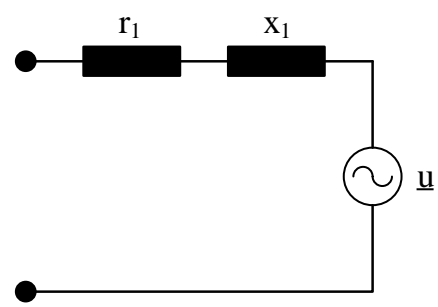

Positive sequence

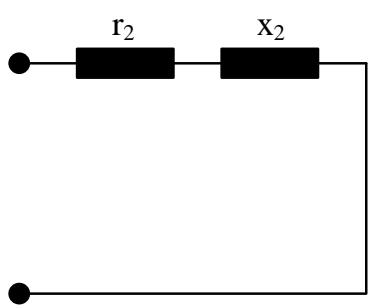

Negative sequence

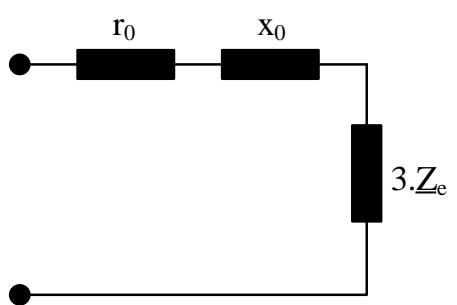

Zero sequence

Fig. 4 Asynchronous machine complete short-circuit subtransient model (adapted from Ref. [27]).

synchronous generators, were parameterized according to Funmilayo and Butler-Purry [26]. DGs penetration levels were defined at $20 \%, 50 \%$ and above of $100 \%$ of the total load supplied by the substation. This analysis considered each and all network nodes for DG placement and fault simulation, one node at a time.

In the second and third cases, three types of distributed injection technologies were used. Asynchronous generators, which can operate as a standard asynchronous machine or a doubly fed induction machine, were selected from the Power Factory library with a power of $400 \mathrm{~kW}$. On the other hand, due to the low power of the synchronous generators these had to be parameterized according to the data provided [26] and a power of $400 \mathrm{~kW}$. It was decided to choose the same power so that a better comparison could be made between the alternatives.

Short-circuit analyses were carried out, for all generator technologies, through the "complete method" where the internal voltage source is initialised by a preceding load flow calculation, determining subtransient and transient fault currents using subtransient and transient voltage sources and impedances. Fig. 4 shows the short-circuit subtransient model of an asynchronous machine. The transient model does not have the voltage source in the positive sequence. The positive sequence impedance is calculated according to Eqs. (1)-(4). The negative sequence impedance is set equal to the positive sequence impedance (Eq. (5)) [27].

$$
\begin{gathered}
z_{1}=r_{1}+j x_{1} \\
z_{1}=1 / I_{L R}
\end{gathered}
$$

$$
\begin{gathered}
x_{1}=z_{1} / \sqrt{1+r_{L R}^{2}} \\
r_{1}=x_{1} \times r_{L R} \\
z_{2}=z_{1}
\end{gathered}
$$

where:

$z_{1}$ and $z_{1}$ : positive and negative sequences impedances, respectively $(\Omega)$;

$r_{1}$ : positive sequence resistance $(\Omega)$;

$x_{1}$ : positive sequence reactance $(\Omega)$;

$I_{\mathrm{LR}}$ : locked rotor current $(\mathrm{A})$;

$r_{\mathrm{LR}}$ : locked rotor resistance $(\Omega)$.

DFIMs, in short-circuit analysis, are modelled with an equivalent synchronous machine and have not any coupled power electronics interface.

\section{Simulations, Results and Discussion}

\subsection{First Case}

In the first case an exhaustive analysis was carried out, with of 650 simulations, evaluating the impact of increasing synchronous machine based DG penetration levels in the test network. The flowchart for an exhaustive analysis is shown in Fig. 5, adjusted for each value of the DG unit analyzed. In all cases, the current variation, $\Delta I$, was calculated as the difference between the fault currents without DG and with DG, as a percentage of the fault current without DG given by Eq. (6), to verify the behavior of the fault current for the various DG penetration values, comparing them to the corresponding values of the network in operation without any DG.

$$
\Delta I(\%)=\frac{I_{S D G}-I_{C D G}}{I_{S D G}}
$$




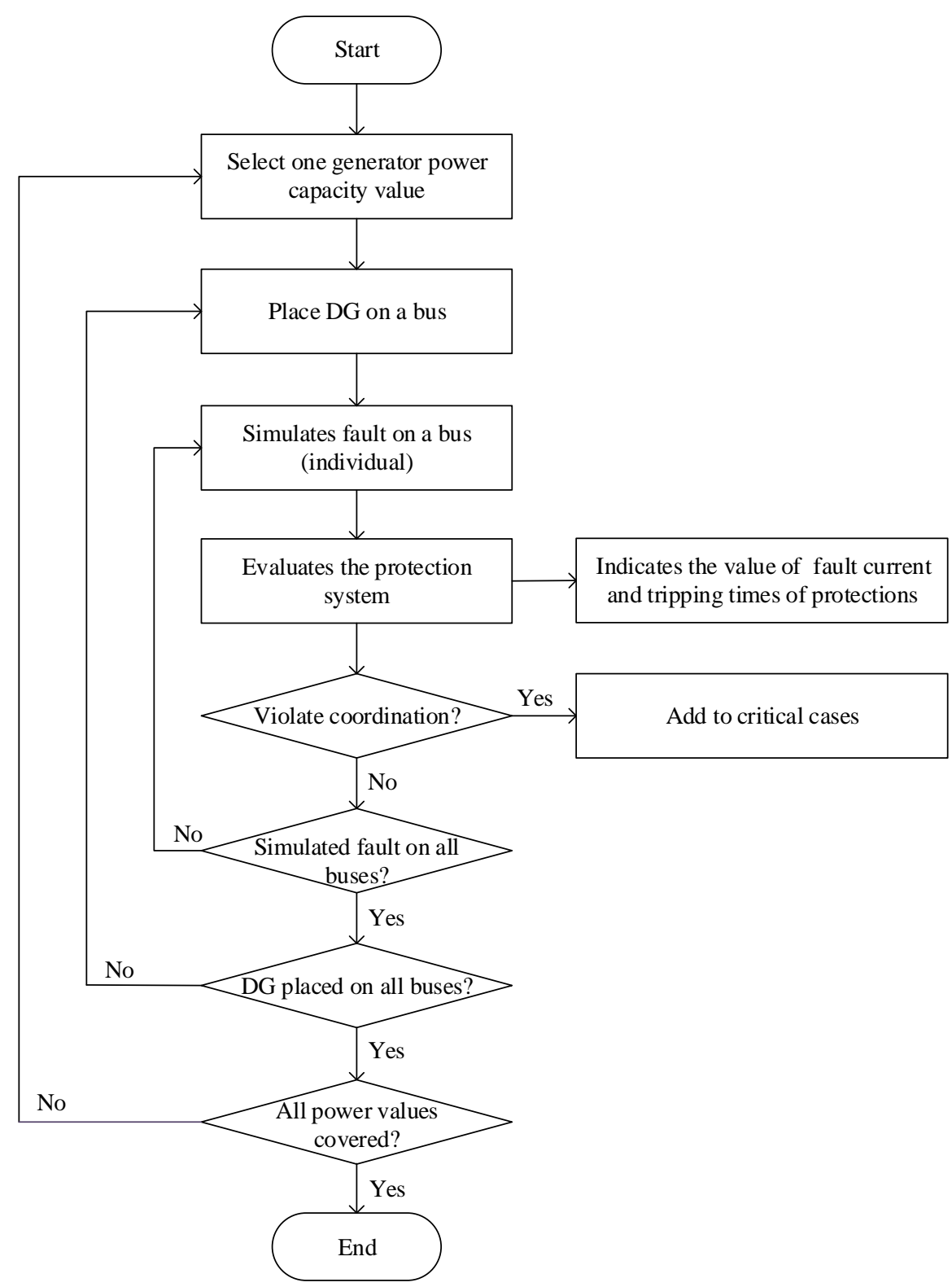

Fig. 5 Flowchart for exhaustive analysis of default occurrences, for each different power value of DGs.

where:

$\Delta I$ : current variation;

$I_{\mathrm{SDG}}$ : short-circuit current without DG;

$I_{\mathrm{cDG}}$ : short-circuit current with DG.

The evolution of the current variation registered in Fig. 6 shows the number of cases, translated into percentage, in six intervals. Each interval refers to the number of cases in which the current variation occurred within the indicated limits $(0-15 \%$, $16 \%-30 \%, \ldots)$. The interval $>100 \%$ means that the current variation, established by Eq. (6) is greater than
$100 \%$, which occurs, especially, when the DG is 2.5 MVA. The placement of 0.406 MVA DG units led to an increase, of the short-circuit current variation $(\Delta I)$, by a maximum of $27 \%$ compared to the case of the network without DG. For 1.075 MVA DG units this variation was higher. With the placement of $2.5 \mathrm{MVA}$ DG units, the ration between the value of the fault currents with DG and without DG was even higher when compared to the previous ones, which may lead, in most cases, to loss of coordination, as can be seen in Fig. 6. 


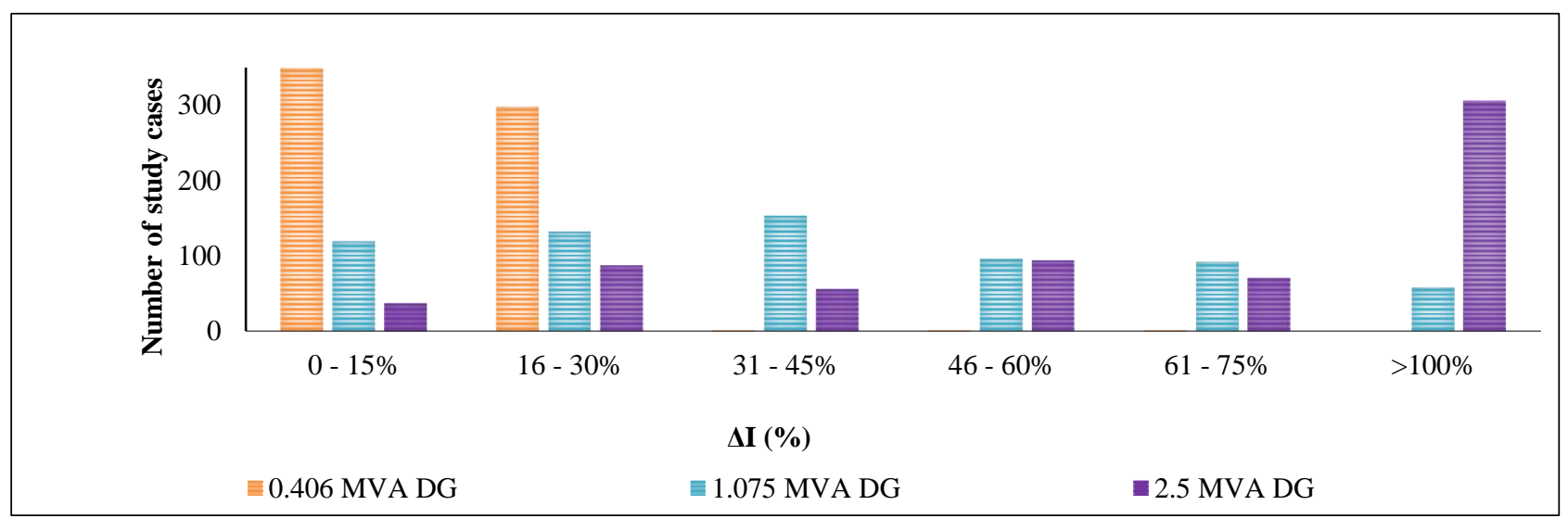

Fig. 6 Evolution of short-circuit current variation with different power values of synchronous distributed generators.

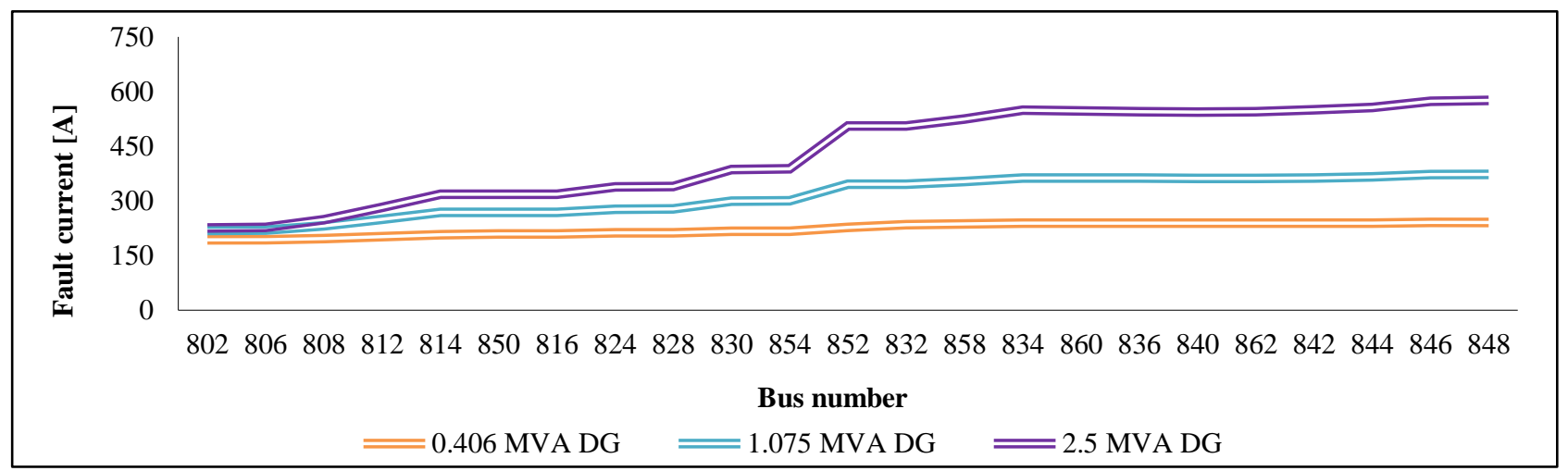

Fig. 7 Evolution of fault current with different power values of synchronous distributed generators.

The 0.406 MVA DG units did not bring any protection coordination problems. However, by increasing the injection value to 1.075 MVA DG units, the first problems arose. The placement of DG downstream of bus 852 led to the loss of coordination at all laterals of the distribution network. By placing a 2.5 MVA DG unit on each bus at a time and simulating faults in lateral feeders, there was loss of coordination in almost all cases. Predictably, according to the literature, for an injection value close to or greater than the total network load, short-circuit currents are much higher than the initial values, leading to loss of coordination of the protection system $[18,26,28]$. Fig. 7 shows the evolution of the fault current when a DG unit, of each type, was placed on each bus, with the purpose of the DSO being able to check the acceptable power limits for the injections in each bus, to be able to exert influence on the DG interconnection authorization decisions.
The length of the circuit path to the fault is one of the factors affecting the value of the fault current [29-31]. In this sense, the length of each section was calculated, from the substation to the terminal node of each lateral feeder, and it was found that the longest section incorporates node 848, which is confirmed by Fig. 7 . The simulations of short-circuits in several buses along the network allow verifying that the integration of DG units makes the current have different values for the various levels of penetration of DG.

In this sense, Fig. 8 shows that the placement of a DG at the beginning of the main network feeder, at bus 806 , and another at the end, bus 836 , cause the recloser to sense a current which is very different from the fault, for short-circuit simulated at the bus furthest from the substation. When the power of the new integrated DG is $0.406 \mathrm{MVA}$, the protection system continues to operate correctly, the fuse clearing fault, without the need for the recloser to operate. When the power of the 


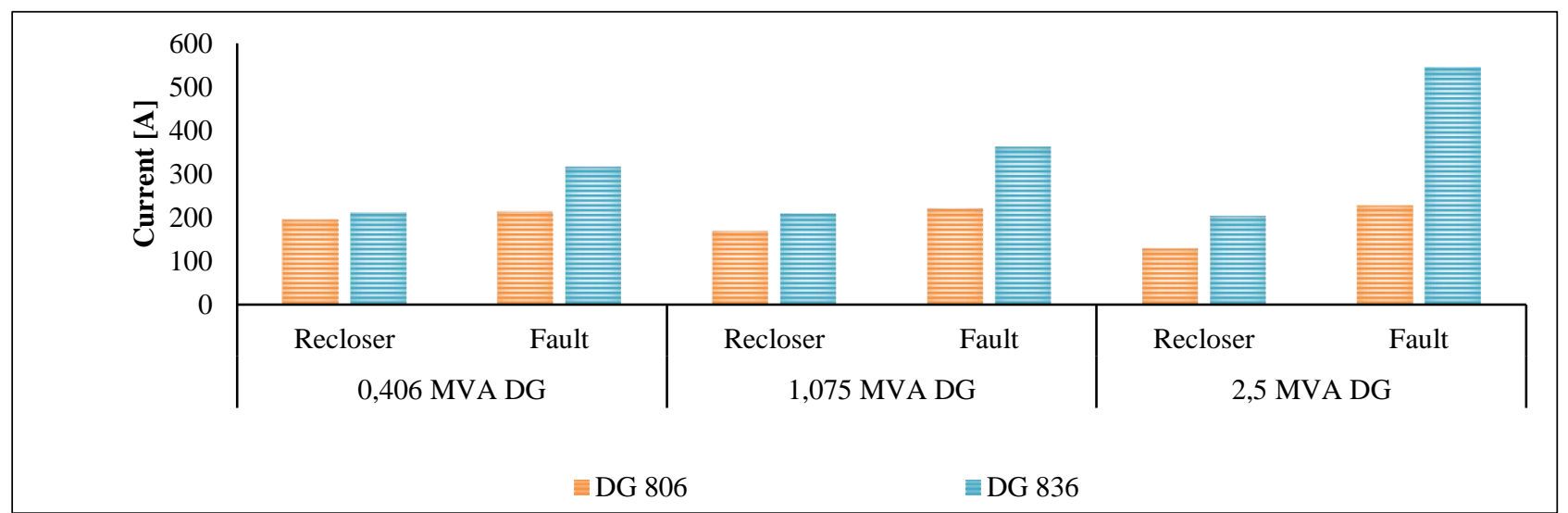

Fig. 8 Current behavior seen by the recloser and fault, when faults are simulated at node 848, and DG units connected at 806 and 836 .

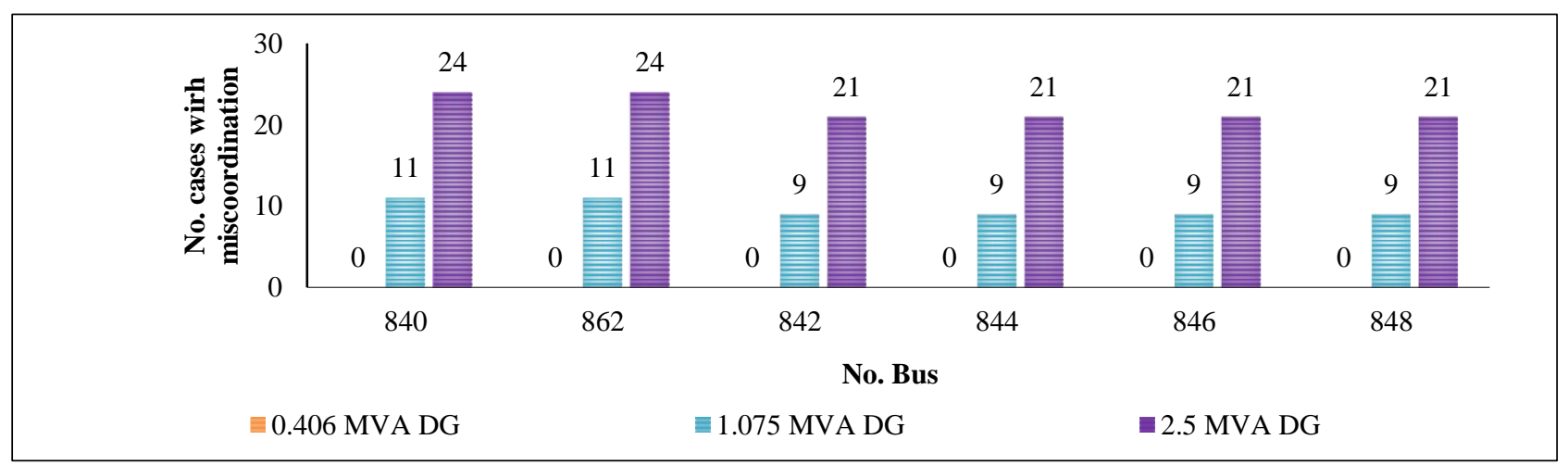

Fig. 9 Miscoordination cases vs. bus number for all three DG types.

simulated DG unit is increased to 1.075 MVA, placed at the bus 836, the coordination between the protections is lost, the fault current being higher than the current sensed by the recloser. The same happens when the simulated DG unit power is increased to 2.5 MVA, which causes miscoordination of the protection system, the current seen by the recloser being much less than the fault current. These results confirm it is advantageous for the DSO to have the location of new DG closer to the supply spot in order to be able to ensure a normal operation of the existing conventional protection system.

According to the results obtained, illustrated in Fig. 9 , the places most susceptible to the occurrence of protection coordination fault are the lateral terminal nodes 840,848 and 862 . Additionally, in order to check if there was any difference on the response of the protection system, node 842 was still selected because it is on the same lateral as 848 , but at the beginning.

The placement of DG units, either close to the feeders or not, always leads to problems of protection coordination. Thus, the nodes selected for DG location were 836 (next to terminals 840 and 862), 858 (at the beginning of the derivation of the lateral feeders), 824 , 814 and 806 because they are in the middle of the feeder, prior to a voltage regulator and near the substation, respectively. Buses 836 and 858 are the ones that can raise the most relevant coordination problems as they are farthest from the substation.

\subsection{Second Case}

Considering the results obtained in the first case, in the second case, DGs were placed on several buses, $858,836,824,814$ and 806 , and short-circuits were simulated in lateral feeders at buses $842,848,862$ and 840 , to analyze in each case the behavior of the 
protection system, with different types of generators: standard asynchronous machine, doubly fed induction machine and synchronous machine.

When placing two DG units at buses 858 and 836, results were similar for the three types of generators, the protective devices were coordinated, operating normally. Increasing the number to three DG units the coordination was lost. In Fig. 10, one case of lack of coordination is illustrated, with a short-circuit simulated at bus 848. The red curves are the characteristic curves of the recloser, the fast tripping curve being intersected at $0.527 \mathrm{~s}$. The blue curves are the fuse characteristic curves, of which the TC is intersected at $0.464 \mathrm{~s}$, i.e. fuse would blow before the recloser operates.

Recloser fast tripping times were very close to each other for all three types of machines. However, this was not the case for the fuse response: in the case of synchronous machines, the fuse shows a shorter operating time than in the case of induction machines, when it was faster to operate, causing loss of coordination.

It is possible to obtain a critical time delay of the recloser by determining the difference between the fuse tripping time and recloser operation time, so that some variations can be seen. By setting a DG at bus 858 and simulating a fault at bus 842 , for the three types of machines, using the same number of machines, different delay times are obtained, as illustrated in Fig. 11.

On the other hand, with a DG at bus 824, half way of the main feeder, the results for the three types of machines are different. The number of generators required for asynchronous machine miscoordination is greater, followed by the DFIM and the synchronous machines, with 5, 4 and 3 generators, respectively. When locating DG at bus 814, the asynchronous machine and the DFIM both need the same number of generators to cause loss of coordination between protection devices. If the DGs are located at bus 806, close to the substation, even more machines are required to cause loss of coordination, the capacity of
DGs units becoming much higher than the total network load, causing the voltage limits, $\pm 5 \%$ around the nominal value of $\mathrm{V}$, to be exceeded on the buses and the reliability of the grid being affected. The required average number of DGs at each bus to cause loss of coordination of protection devices is shown in Fig. 12.

According to the results obtained in the simulations, and taking into account Fig. 12, the potential level of penetration of DG based on asynchronous machines is higher in relation to DFIM or synchronous machines, from the point of view of ensuring coordination on the conventional protection system, especially in the buses closest to the substation. However, given the current market trend, influenced by the fact that DFIMs are more efficient and have better characteristics than conventional asynchronous machines, one can say that it is beneficial to the DSO when DFIM-based DG is used instead of synchronous machines.

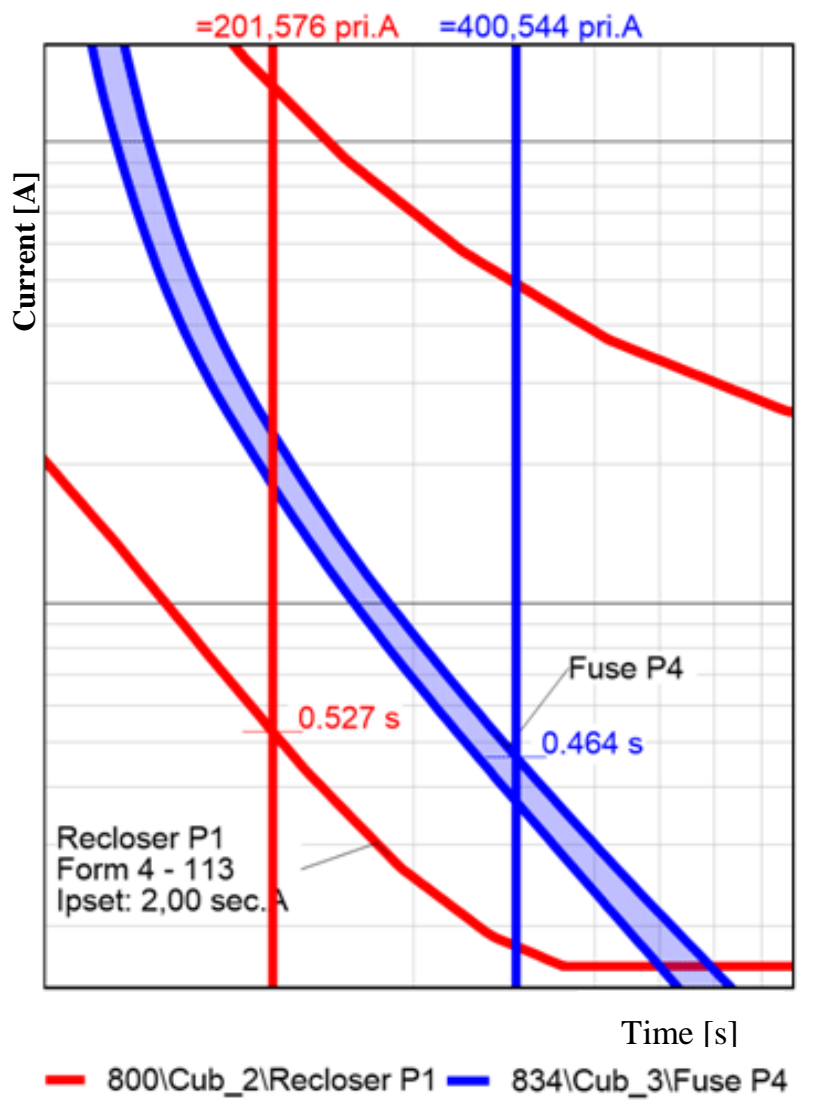

Fig. 10 Miscoordination of protection devices for a fault on bus 848 with a DG on 858, using DFIM. 


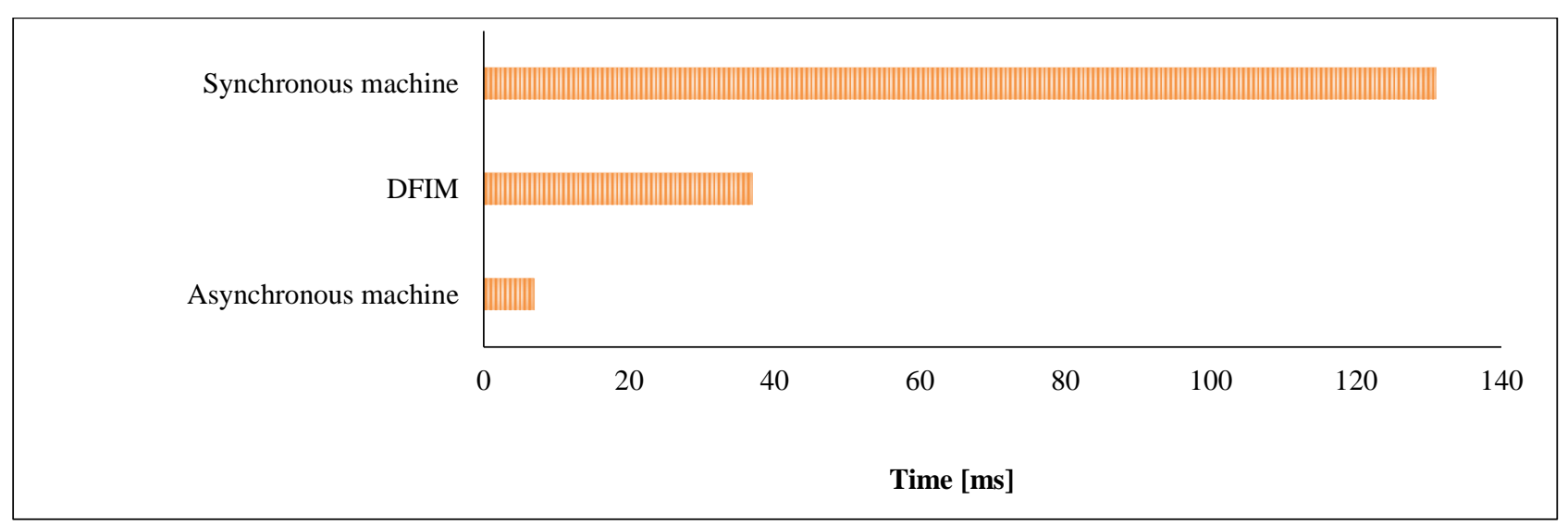

Fig. 11 Variation of the recloser delay times relative to the fuse for the three generator types, with DG at bus 858 and short-circuit at bus 842 .

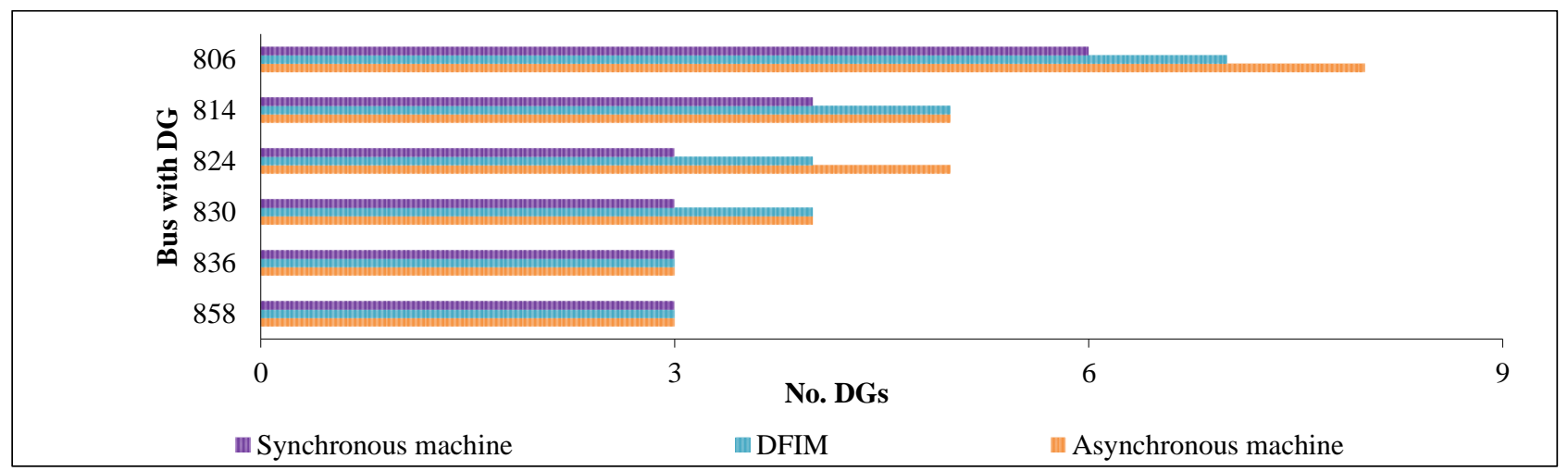

Fig. 12 Number of DGs required for the loss of coordination of the 3 types of generators.

\subsection{Third Case}

In this case multiple DG units were placed in more than one bus. The buses selected for DG placement were the same ones used in the previous cases. Faults were simulated at buses 840,848 and 862 , given that, according to the exhaustive analysis, these are lateral feeders where more cases of loss of coordination occur. Some cases are presented in Tables 2-4 with the different types of generators, corresponding to cases with no coordination between protections. The data in the tables, indicate the number of DG units that led to loss of coordination, along with the location of faults and DG.

The behavior of each technology with multiple DGs on multiple buses differs in most cases studied. According to the results it is possible in some cases to have a larger number of DGs on multiple buses while simultaneously ensuring the correct operation of the
Table 2 DGs placed on multiple buses equipped with asynchronous machines.

\begin{tabular}{lllllllll}
\hline \multirow{2}{*}{ Case } & \multirow{2}{*}{ Fault } & \multicolumn{7}{c}{ DG } \\
\cline { 2 - 7 } & & 858 & 836 & 824 & 814 & 806 & total \\
\hline 1 & 848 & 1 & 1 & 1 & 0 & 0 & 3 \\
2 & 840 & 1 & 1 & 1 & 0 & 0 & 3 \\
3 & 862 & 0 & 1 & 1 & 1 & 0 & 3 \\
4 & 848 & 0 & 0 & 2 & 2 & 0 & 4 \\
5 & 862 & 0 & 0 & 2 & 2 & 0 & 4 \\
6 & 848 & 0 & 0 & 3 & 1 & 1 & 5 \\
\hline
\end{tabular}

Table 3 DGs placed on multiple buses equipped with DFIM.

\begin{tabular}{llllllll}
\hline \multirow{2}{*}{ Case } & \multirow{2}{*}{ Fault } & \multicolumn{5}{c}{ DG } & \multirow{2}{*}{\begin{tabular}{l} 
No. DGs \\
\cline { 3 - 7 }
\end{tabular}} \\
\cline { 2 - 7 } & 858 & 836 & 824 & 814 & 806 & total \\
\hline 1 & 848 & 1 & 1 & 1 & 0 & 0 & 3 \\
2 & 840 & 1 & 1 & 0 & 0 & 0 & 2 \\
3 & 862 & 0 & 1 & 1 & 1 & 0 & 3 \\
4 & 848 & 0 & 0 & 2 & 2 & 0 & 4 \\
5 & 862 & 0 & 0 & 2 & 2 & 0 & 3 \\
6 & 848 & 0 & 0 & 2 & 1 & 1 & 4 \\
\hline
\end{tabular}


Table 4 DGs placed on multiple buses equipped with synchronous machines.

\begin{tabular}{llllllll}
\hline \multirow{2}{*}{ Case } & \multirow{2}{*}{ Fault } & \multicolumn{7}{c}{ DG } & No. DGs \\
\cline { 3 - 7 } & & 858 & 836 & 824 & 814 & 806 & total \\
\hline 1 & 848 & 1 & 1 & 0 & 0 & 0 & 2 \\
2 & 840 & 1 & 1 & 1 & 0 & 0 & 3 \\
3 & 862 & 0 & 1 & 1 & 1 & 0 & 3 \\
4 & 848 & 0 & 0 & 2 & 1 & 0 & 3 \\
5 & 862 & 0 & 0 & 2 & 1 & 0 & 3 \\
6 & 848 & 0 & 0 & 2 & 1 & 0 & 3 \\
\hline
\end{tabular}

protection system, when compared with the case of integration of various DGs on a single bus, providing the DSO information about the performance of the protection system when DGs are placed on multiple buses. Synchronous machines do not allow the integration of as many DGs as asynchronous machines before loss of coordination occurs.

\section{Conclusions}

This paper presents the results of a comprehensive analysis to assess the performance of a distribution network when there is integration of DGs units, identifying the situations when there is lack of coordination of the recloser-fuse protection scheme. In those cases where there is lack of financial resources to fully modernize the distribution network, the present paper shows it is possible to maintain the conventional protection system, even integrating several DG technologies in the network. The integration of a 0.406 MVA DG unit, 20\% of the nominal network load, does not affect the correct operation of the protection system. By duplicating DG penetration, problems began to arise in the protection system operation. In lateral feeders these problems were most notable when faults were simulated by locating DG anywhere on the network. Through this analysis it was possible to verify the limitations of each bus, regarding the penetration of DG, when there is no change in the conventional protection system.

The performance of the network with different DG technologies, always placed on the same bus, was also assessed. The use of synchronous machines presented the worst results, whereas the use of asynchronous machines allows the integration of a higher number of DG units without compromising the coordination between recloser and fuses.

When placing multiple power injections based on asynchronous machines along the network, there were cases where it was possible to connect four DG units without jeopardizing the conventional protection system operation, DG penetration representing $75 \%$ of the total network load. Contrasting with these results, in the case of synchronous generators only two DGs were enough to cause coordination problems. According to the results, given the parameters defined for each technology, it can be said that the use of asynchronous machines allows the integration of more DG units in the distribution network when compared to synchronous machines.

The penetration of DG units, the types of technology used, the distribution network configuration, the network protections, the capacity of the electrical network to operate with bidirectional power flows, were some of the aspects that interfered on the integration of DG units. It is straightforward to extend the methodology used in the paper to larger networks if the network is split into zones and each zone is individually analyzed, one feeder at a time, in order to assess coordination between the available protection devices. This is a realistic approach, since, in most cases, the assessment of network operation by the DSO is driven by the need for a gradual response to new DG projects. A way to mitigate the cases in which the protection coordination is lost was proposed by Abreu et al. [9], using settings adjustments of the reclosers' parameters. In a context of the need for parsimony in the use of capital, it is prudent to carry out a careful and detailed analysis of the operational implications, for the management of the network and protection systems, of the interconnection of new DG units.

\section{Acknowledgments}

The authors acknowledge the support provided by 
project grant UIDB/00308/2020 and Fundação para a Ciência e a Tecnologia (FCT), grant number SFRH/BD/129958/2017.

\section{References}

[1] Han, Z. 2014 "Protection Coordination in Networks with Renewable Energy Sources.” M.Sc. thesis, University of Manchester.

[2] Freris, L., and Infield, D. 2008. Renewable Energy in Power Systems, 1st ed. Hoboken: John Wiley \& Sons.

[3] Freitas, W., Vieira, J. C. M., Silva, L. C. P. da, Costa, V. F. da, and Lemos, F. A. B. 2006. "Comparative Analysis between Synchronous and Induction Machines for Distributed Generation Applications." IEEE Trans. Power Syst. 21 (1): 301-11. doi: 10.1109/TPWRS.2005.860931.

[4] Georgilakis, P. S., and Hatziargyriou, N. D. 2013. "Optimal Distributed Generation Placement in Power Distribution Networks: Models, Methods, and Future Research." IEEE Trans. Power Syst. 28 (3): 3420-8. doi: 10.1109/TPWRS.2012.2237043.

[5] Zhan, H., Wang, C. S., Wang, Y., Yang, X. H., Zhang, X., Wu, C. J., and Chen, Y. H. 2016. "Relay Protection Coordination Integrated Optimal Placement and Sizing of Distributed Generation Sources in Distribution Networks." IEEE Trans. Smart Grid 7 (1): 55-65. doi: 10.1109/TSG.2015.2420667.

[6] Esmaeilzadeh, M., Ahmadi, I., and Ramezani, N. 2018. "Optimal Distributed Generation Planning in Radial Distribution Networks Considering Protection Coordination Limits." Iran. J. Electr. Electron. Eng. 14 (2): 178-87. doi: 10.22068/IJEEE.14.2.178.

[7] Balamurugan, K., Srinivasan, D., and Reindl, T. 2012. "Impact of Distributed Generation on Power Distribution Systems." Energy Procedia 25: 93-100. doi: 10.1016/j.egypro.2012.07.013.

[8] Kumawat, M., Gupta, N., Jain, N., and Saxena, D. 2015. "Optimal Distributed Generation Placement in Distributed Networks: A Review." In International Conference on Electrical, Electronics, Signals, Communication and Optimization (EESCO), p. $6 . \quad$ doi: 10.1109/EESCO.2015.7254023.

[9] Abreu, P., Santos, I., Martins, E., and Gomes, A. 2019. "Efficient Approaches to Adapt Radial Network Protection Systems to Distributed Power Injections." In IECON 2019 45th Annual Conference of the IEEE Industrial Electronics Society, vol. 1, pp. 2166-71. doi: 10.1109/IECON.2019.8927633.

[10] Yuan, H., Guan, Z., Kong, H. J., Zhang, B. H., Huang, R. M., Wu, W. M., Li , Y., and Guo, D. Y. 2015. "Impact of Renewable Energy Integration on Overcurrent Protection in Distribution Network." In Proc. 2015 27th Chinese
Control Decis. Conf. CCDC, pp. 5090-5. doi: 10.1109/CCDC.2015.7162835.

[11] Rizzo, R., Piegari, L., and Tricoli, P. 2012. "A Comparison between Line-Start Synchronous Machines and Induction Machines in Distributed Generation." Prz. Elektrotechniczny 88 (5B): 187-9.

[12] Beainy, A., Maatouk, C., Moubayed, N., and Kaddah, F. 2016. "Comparison of Different Types of Generator for Wind Energy Conversion System Topologies.” In 3rd Int. Conf. Renew. Energies Dev. Countries. doi: 10.1109/REDEC.2016.7577535.

[13] Saini, S. 2013. "Review of Doubly Fed Induction Generator Used in Wind Power Generation." Int. J. Environ. Sci. Dev. Monit. 4 (3): 53-6.

[14] Lebsir, A., Bentounsi, A., Benbouzid, M. E. H., and Mangel, H. 2015. "Electric Generators Fitted to Wind Turbine Systems: An Up-to-Date Comparative Study." J. $\begin{array}{llll}\text { Electr. } & \text { Syst. } & 11 & \text { (3): }\end{array}$ https://hal.archives-ouvertes.fr/hal-01213120.

[15] Tiwari, A. R., Shewale, A. J., Gagangras, A. R., and Lokhande, N. M. 2014. "Comparison of Various Wind Turbine Generators.” Multidiscip. J. Res. Eng. Technol. 1 (2): 129-35.

[16] Ramalho, P. 2008. "Parques Eólicos com 'Ride-Through Through Fault': Nova parametrização dos sistemas de protecção." M.Sc. thesis, University of Porto. (in Portuguese)

[17] Sampaio, J. 2015. "Identificações de soluções de controlo para ligações HVDC.” M.Sc. thesis, University of Porto. (in Portuguese)

[18] Abdel-Galil, T. K., Abu-Elanien, A. E. B., El-Saadany, E. F., Girgis, A., Mohamed, Y. A. R. I., Salama, M. M. A., and Zeineldin, H. H. 2007. Protection Coordination Planning with Distributed Generation Technical Report. doi: 10.13140/RG.2.2.35416.80649.

[19] Ilik, S. C., and Arsoy, A. B. 2017. "Effects of Distributed Generation on Overcurrent Relay Coordination and an Adaptive Protection Scheme." Int. Conf. Sustain. Energy Eng. 73: 1-10, doi: 10.1088/1755-1315/73/1/012026.

[20] Hao, K., Achanta, S. V., Fowler, J., and Keckalo, D. 2017. "Apply a Wireless Line Sensor System to Enhance Distribution Protection Schemes." In 70th Annual Conference for Protective Relay Engineers (CPRE), doi: 10.1109/CPRE.2017.8090006.

[21] Dawoud, M. A., Ibrahim, D. K., and Gilany, M. 2017. "Restoring Recloser-Fuse Coordination in Radial Distribution Networks with Distributed Generation." Ninet. Int. Middle East Power Syst. Conf., pp. 170-5. doi: 10.1109/MEPCON.2017.8301180.

[22] Jamali, S., and Borhani-Bahabadi, H. 2017. "Self-adaptive Relaying Scheme of Reclosers for Fuse Saving in Distribution Networks with DG." Int. J. Power Energy Res. 
1 (1): 8-19. doi: 10.22606/ijper.2017.11002.

[23] Chaitusaney, S., and Yokoyama, A. 2008. "Prevention of Reliability Degradation from Recloser-Fuse Miscoordination due to Distributed Generation." IEEE Trans. Power Deliv. 23 (4): 2545-54. doi: 10.1109/TPWRD.2007.915899.

[24] Owuor, A. J. O., Munda, J. L., and Jimoh, A. A. 2011. "The IEEE 34 Node Radial Test Feeder as a Simulation Testbench for Distributed Generation." In IEEE Africon 2011: The Falls Resort and Conference Centre, pp. 1-6. doi: 10.1109/AFRCON.2011.6072095.

[25] Mwakabuta, N., and Sekar, A. 2007. "Comparative Study of the IEEE 34 Node Test Feeder under Practical Simplifications." In Proceedings of the 39th North Am. Power Symp. NAPS, pp. 484-91. doi: 10.1109/NAPS.2007.4402354.

[26] Funmilayo, H. B., and Butler-Purry, K. L. 2009. “An Approach to Mitigate the Impact of Distributed Generation on the Overcurrent Protection Scheme for Radial Feeders." In Proceedings of the 2009 IEEE/PES
Power Systems Conference and Exposition, pp. 1-11. doi: 10.1109/PSCE.2009.4840233.

[27] Digsilent, Power Factory. 2019. "Technical Reference Documentation Asynchronous Machine." https://www.digsilent.de.

[28] Naiem, A. F., Hegazy, Y., Abdelaziz, A. Y., and Elsharkawy, A. 2015. "A Novel Protection Methodology for Distribution Systems Equipped with Distributed Generation.” Int. Electr. Eng. J. 6 (10): 2048-57.

[29] Sarabia, A. F. 2011. "Impact of Distributed Generation on Distribution System.” M.Sc. thesis, Aalborg University.

[30] Fernandes, P. 2012. "Modelização e análise de desempenho de redes de distribuição mistas." M.Sc. thesis, Instituto Superior de Engenharia do Porto. (in Portuguese)

[31] Mora-Florez, J., Alzate-Gonzalez, N., and Perez-Londono, S. 2015. "Sensitivity Analysis of Fault Locators in Power Distribution Systems Considering Distributed Generation." In Proceedings of the 23rd International Conference on Electricity Distribution, pp. 15-8. 